\title{
Continuous Education Of Older Employees: Cost Or Benefit?
}

\author{
Jana Žnidaršič, University of Ljubljana, Slovenia
}

\begin{abstract}
The complexity of consequences of population ageing is posing a threat to the EU macroeconomic performance, as well as to the competitiveness of every single enterprise. In this context, increases in participation and employment rates for older workers are essential to help sustain economic growth, and manage the rising financial burden on social protection systems. Between HRM approaches, policies and instruments - continuous education of older employees - seems to be extremely important when striving to prolong employees' working life. Up-to-date knowledge improves older workers' workability and enables people to remain "employable". Moreover, it is beneficial for self-confidence, which in turn influences an intrinsic motivation for prolonging working life.The aim of this paper is to highlight the importance of continuous education of older employees and benefits that life-long learning brings to company. However, stereotyping older employees still puts numerous obstacles for continuous education and this is why the paper sheds light upon myths that need to be avoided. Simultaneously, real facts considering older employees' education are brought up to the surface. Finally, the paper offers many suggestions for long-life learning with special emphasize on improving education of older employees.
\end{abstract}

Keywords: Ageing Workforce; Education of Older Employees; Life-Long Learning; Active Ageing; Age Management

\section{INTRODUCTION}

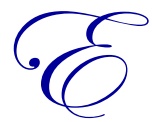

urope today is facing unprecedented demographic change. The population ageing is posing a threat to the EU macro-economic performance, since it may seriously decrease the competitiveness of European economy as well as every single enterprise. In this context, increases in participation and employment rates for older workers are essential to help sustain economic growth and manage the rising financial burden on social protection systems. Therefore, older workers are becoming an important target group within European policy whose needs and requirements must be considered.

Consequently, the traditional way of viewing ageing workers as employees with deficits that should exit the labour market early is making way for an approach where ageing workers are seen as a valuable resource. However, older workers would prolong their working life only when they are able to stay and willing to stay.

Analyzing the whole complexity of factors that impact on older worker' labor-market participation would go beyond the scope of this paper, which focuses on learning (education and training) of older employees. There is no doubt that possessing up-to-date knowledge certainly contributes a lot to older employees' workability and when accompanied with suitable economic policies - also to their employability.

Reviewing current research literature (including demographic trends, myths concerning physical and cognitive changes with age, older workers' ability to learn, work ability in general etc.), and presenting new empirical findings, the contribution of this paper is enriched by suggesting innovative ways of thinking to support active ageing policies in general and those that reflect older workers' learning.

By examining emerging career development concepts, theories and learning frameworks for ageing workers, the first part gives a broad view of the subject matter while shedding the light on the discussion concerning 
costs and benefits of continuous education of older employees. The central part of the paper provides evidences of numerous positive effects of educating older employees, be it for company or older worker. The final part identifies ways of breaking traditional patterns to extend working lives and to assist working beyond retirement age, with special emphasize on learning practices. Closing the paper, a big pool of "older-workers' friendly" learning practices, guidelines and initiatives that support efficient learning are suggested.

\section{CAPABILITY AND DEVELOPMENT OF OLDER WORKERS: APPROACHES AND THEORIES}

Nowadays approaches focusing on the development of the workforce during the second half of the career can be split into two directions (Thijssen \& Rocco, 2010). The first approach links up with general principles and factors that might promote the willingness and capability of older workers to (re)train and involves lifelong learning and retraining projects for people who are employed and unemployed (Kaufman, 1995; Thijssen, 1992). Many authors have found that significant declines in cognition often manifest themselves when people are in their 60s or 70 s, contrary to the deficiency hypothesis (beginning at 35) (Craik \& Salthouse, 2000; Schaie, 1990; Staudinger \& Lindenberger, 2003). A second, less known, contemporary approach focuses on explaining the huge individual differences in qualifications, which are important for professional employability and flexibility, among older workers during the second half of their careers. That question becomes more interesting since such individual differences seem to be increasing with age.

According to these modern theoretical ideas, experience is of much greater importance to individual flexible employability than age, although age and experience cannot be viewed as separate entities. In the late 1980s, the experience concentration theory was developed while considering the differences between specific and generic human capital (Mincer, 1974). The experience concentration theory focuses on a twofold basic premise concerning the connection between age and experience (Thijssen, 1992; Thijssen \& Van der Heijden, 2003).

Someone's experience built up over a certain period may range from relatively restricted (concentration) to relatively broad (variation). With increasing age, the two tendencies come on the surface - an increase in experience but without much diversity. Younger age groups generally exhibit a pattern involving more experience variation; older age groups generally offer more experience concentration. Concentration has an effect often found with specialists: experiencing a fairly limited variety of experiences quickly results in a certain expertise and routine, realising high labour efficiency within a small range of tasks. With age, experience concentration may become evident in three important domains (Thijssen \& Rocco, 2010):

- $\quad$ learning-strategic domain: the structure of educational experience at an older age often remains restricted to informal. In that case we speak of schooling experience. The total range of strategies to learn new things may, with age, even be reduced to what is sometimes called incidental learning. Formal activities are used less and less. From a comparative viewpoint, a modest education background is more likely to result in a restriction of formal learning skills and avoidance of future training opportunities;

- $\quad$ occupational domain: the structure of the working experience at an older age often remains restricted to minor task adaptations; drastic changes in the task package or the working environment are avoided as much as possible. Mobility is avoided as well;

- $\quad$ sociocultural domain: the structure of the networking experience - social environments and the cultural group layers within which people move - will, with age, often be restricted to a shrinking and rigid network, to a small circle (we speak of network concentration). Usually, network innovations at an older age are the exception.

A certain level of experience concentration seems to be beneficial, while compensating for age-related losses in physical and cognitive capabilities. However, continuous learning, network and even occupational concentration can substantially lower older employee' ability to perform on the job well. Thus, the importance of early recognition of experience concentration is obvious, as the earlier this tendency is recognized, the easier it can be corrected (Thijssen \& Van der Heijden, 2003).

As already mentioned, another important dilemma appears when considering various physical and cognitive capabilities and their changes with age. Here, numerous researches come up with very different findings. 
While age-related changes in mental and physical function are inevitable, they do not invariably lead to incapacity or reduced performance and productivity at work. Actually, even employees with diminished physical or cognitive function may continue to work effectively as they age. We need to know that most jobs do not require performance at full capacity. Besides, while various physical and cognitive capabilities decline with age, there is great interindividual variation in these normative trends, much greater than between younger persons (Silverstein, 2008). Third, older individuals can often compensate for age-related losses with relatively age stable strategies and skills related to their experience and expertise, although - as we mentioned above - the relationships are complex and the literature is mixed (Morrow et al., 1994; Meinz and Salthouse, 1998; Charness et al., 2001).

Based on a comprehensive review Salthouse (2006) has concluded that while many types of cognitive and physical performance are improved at all ages with training and practice, this does not appear to change the rate at which capability declines with age. In other words, despite the fact that age-related declines continue at the same rate as they do in workers with less experience and practice, training, practice and experience can enhance performance at older ages and can often result in older workers outperforming younger ones.

It is crucial to note that research has not found any consistent relationship between age and overall work performance. For Example, Griffiths (1997) provides a useful summary of the scientific literature and states that most reviews and meta-analyses report little consistent relationship between ageing and work performance. Evidence from classical studies from the medical field indicating that work performance capacities decline with age, only relates to some physical abilities (European Centre for the Development of Vocational Training, 2010). More or less similar findings appear when considering correlation between learning and aging. Many researches (ex. Rolland, 2004; Salthouse, Maurer, 1996) show that there are no significant differences in capability for learning among older and younger co-workers. Moreover, numerous scientists (ex. Bass, 1995; Peterson, Wendt, 1995; Sullivan, Duplaga, 1997; Warr, 1998) claim that mental processes and ability to learn - assuming healthy old person - decrease only after his/her 70's.

Worse learning results that are sometimes achieved can be the consequence of lower previous knowledge (poor knowledge base) in comparison with younger counterparts (Sterns, Gray, 1999), different psychological needs - connected with learning process, physical boundaries or different learning stiles (Dunn, 2005). Delgoulet, Marquie, Escribe (1997) have noticed emotional tension and fear, accompanying learning process, especially among lower educated older workers (influencing possibly worse final results).

Sometimes, older workers really are "over the hill", but often not because of their chronological age, but because of their knowledge, which gets "old". Although workplace dynamics affect all workers, lifelong learning remains largely focused on younger and middle-aged workers. While overall participation in lifelong learning appears to be increasing, a persistent gap between younger and older workers remains (European Centre for the Development of Vocational Training, 2010). Among other reasons, stereotyping older employees remains a core factor hampering older people's sustainable labor-market participation and access to training. Stoney in Roberts (2003) talk about "vicious circle", when employers do not invest in older workers' education, on the other hand they reproach them to have out of date knowledge and consequently worse working results and lower employability. Older employees get caught in so called »dysfunctional loop«.

The lack of work training and professional development of older workers has serious implications for employers and the workplace generally (McGregor, Gray, 2002): (1) the absence of training opportunities is likely to manifest itself in less than optimum performance; (2) older workers are likely to find themselves with outdated technical skills and less technologically knowledgeable than those who have undergone training; (3) morale problems emerge when a particular group of workers is marginalized in relation to up-skilling and professional development in employment.

Consequently, such practice may result in so called »self-fulfilling prophecy« with de-motivated older workers who under-perform, have poorer performance appraisals, do not maintain high levels of productivity and receive jobs that are more mundane (Carnevale, Stone, 1994). Older workers face so called »self-image problem« (Kaeter, 1995) based on negative self-perception. 
Such processes are definitely not compatible with recent demographic and labor market trends that should be reflected in the shift from discouraging older workers' activity towards retaining their employability, their knowledge and their wisdom (European Centre for the Development of Vocational Training, 2010). Here, continuous education of older employees seems to be of crucial importance. Worker skills and competency building constitute the critical work ability factors (Ilmarinen et al., 1991). Similarly, according to the human capital theories education increases human capital, regardless of human age (Lazear, 1998). To conclude, successful active ageing requires commitment and involvement from ageing workers and employers in a context that supports learning and recognizes the specific needs ageing workers have.

\section{WORKABILITY - A BASIC PRECONDITION FOR LONGER WORKING LIFE}

According to the Finnish researchers Ilmarinen \& Tuomi (2004), work ability has nothing in common with age, as such. Considering the fact that chronological aging starts at birth and ends at death, anyone in the work force (15-64 years of age) can be considered an aging worker ${ }^{1}$ (Ilmarinen, 2001). Similarly, the newest researches into age and aging confirm that »age is not determined biologically, but is a social construct" (Bohlinger, van Loo, 2010).

A so called 'concept of work ability' (Ilmarinen, 2004) is based on the balance of the workers' resources and the work demands. It may be understood as 'how good is the worker at present, in the near future, and how able is he/she to do his/her work with respect to the work demands, health and mental resources' (Ilmarinen, 2006). When we talk about workability, it is not about the age, but it is about how the workers' human resources are compatible with work demands. Human resources mainly consist of: (1) health and functional capacities (physical, mental, social), (2) education and competence, (3) values and attitudes, and (4) motivation. When this comprehensive set of individual factors is related to (5) work demands (physical, mental), (6) work community and management, and (7) work environment, the outcome can be called the individual work ability (Figure 1).

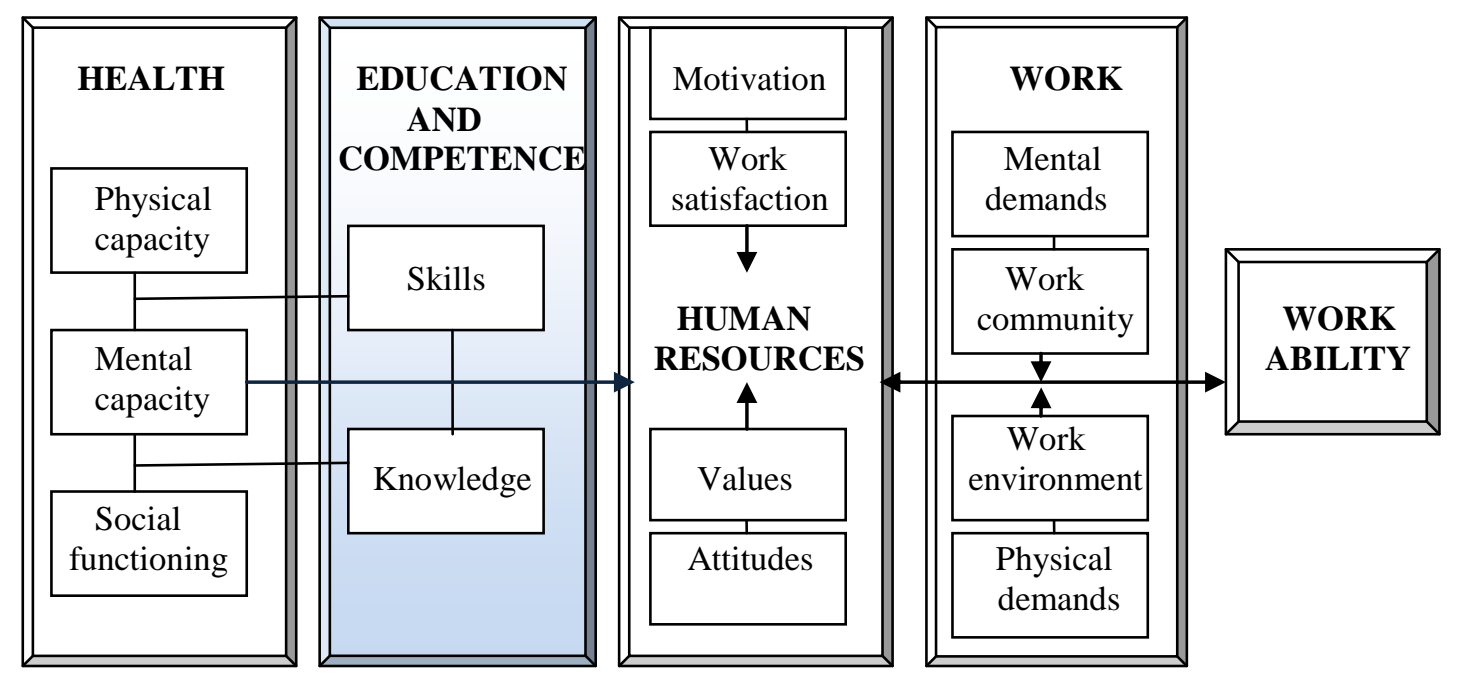

Figure 1: The work ability concept Source: Ilmarinen, 2001.

\footnotetext{
${ }^{1}$ The main reason for the "early" definition of aging among workers from the occupational health point of view is that it gives better possibilities for preventive measures. The need for early action has been emphasized by the low participation rates of workers who are aged 55 years or older and by the early exit of this age group from work life all over the world. However, the definition of an aging worker is generally based on the period when major changes occur in relevant work related functions during the course of work life. Therefore, the ages of 45 or 50 years have often been used as the base criterion for the term "aging worker" (Ilmarinen, 2001).
} 
The worker contributes to his work ability via his health and functional abilities, with knowledge, skills, attitudes and motivation. The workplace influences the work ability through work organizational factors - especially leadership and management issues - by work demands and by the work environment, including social factors.

Four sets of variables have been associated with the preservation or enhancement of workability over time and suggest strategies for intervention: (a) adjustments in physical work environment (physical workload, rest/work schedule, repetitive motion, and regulation of one's own work and breaks); (b) adjustments in the psychosocial work environment (flexible work schedules, teamwork, work experience should be utilized and work roles clarified, agemanagement, skills for supervisors); (c) health and lifestyle promotion (physical exercise, risk factor reduction, occupational health services); and (d) worker skills and competency building with more possibilities for development and training (Ilmarinen et al., 1997; Ilmarinen and Rantanen, 1999; Tuomi et al., 2001).

The work ability concept is a dynamic process that changes greatly throughout an individual's work life. However, good work ability is associated with a high quality of work and the enjoyment of staying in one's job, while also predicts active and meaningful retirement (Tuomi at al, 2001). Moreover, the modern concept and the latest experiences show that there are two main processes that affect the employment rate of aging workers, one being the promotion of work ability, and the other being the development of employability (Figure 2). Employability is a new term describing the actions needed to improve the rate of employment. It includes employment, education and exit policies, a large variety of social and health services, and also, for example, the general prevention of age discrimination. The concept of employability is still developing but it can currently be described mainly by powerful characteristics and infrastructures needed at the level of society for better employment of all age groups (Ilmarinen, 2001).

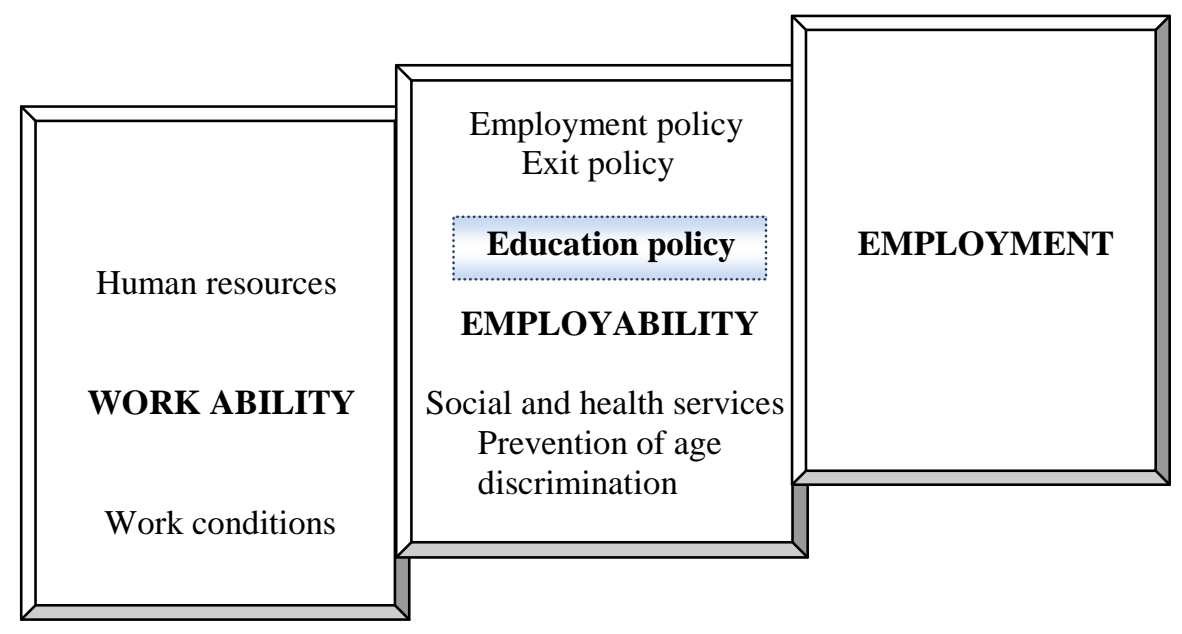

Figure 2: Work ability, employability and employment Source: Ilmarinen, 2001.

Considering the topic of our discussion, we can clearly see that education and competence represent one of the four building blocks for sustainable workability of (older) workers. Moreover, as formulated by the OECD (1996), lifelong learning promotes personality development and improves participation in society and employability, which is understood as the ability to obtain and remain in paid employment.

\section{CONTINUOUS EDUCATION OF OLDER EMPLOYEES: COST OR BENEFIT?}

A key fear amongst employers is that they will not get a sufficient return on their investment in educating and training an older worker, since the costs of training have to be recouped and offset against the likely gains to be had from new or improved skills over time (Newton et al., 2005). Since most skills have a three to five year shelflife, which Meadows (2003) identifies has decreased from seven to eight years, it is worth investing in training 
anyone who will stay with the organization for at least that long. Given that a worker aged 50 may work for a further 15 years or more, and is less likely to change employer in that time (Meadows, 2003), the argument of lowered return on training investment must be discounted.

Actually, there should be no doubt concerning older employees' continuous education and training, since the companies report numerous benefits of up-to-dating knowledge of older workers. Besides higher competence, increased motivation and retention, raised commitment and reduced absenteeism of the workforce (Newton et al., 2005), these benefits include (Naegele, 2007): a) contribution to raising the qualification level and innovation potential of the work force; b) an enhancement of the motivation of younger staff as their own career perspective is reflected in older employees and, at the same time, respect for the job performance of the individual employee is witnessed; c) the intergenerational knowledge transfer and exchange can be advanced; d) positive effects on the quality of a company's products and services; e) in many companies, the involvement of older employees is a guarantor of qualification maintenance, development and transfer within the company; f) for the older employees themselves, their participation in on-the-job further education and training entails an increase in their employability, most notably in the dimensions of flexibility, vertical and horizontal mobility readiness and motivation; g) completing further education and training in earlier career phases raises the willingness to do so in later phases and thus overcomes participation barriers found among older age groups; h) some older workers can be successfully deployed as mentors and teaching staff for both younger colleagues and those of the same age, thus resolving the succession problems.

Moreover, the research (for ex. Ford, 2005) proved the fact that poverty and unemployment erode health and self-esteem of elderly. Simultaneously, the positive effect that education has upon improved individual health has clear economic benefits. Research conducted by the Centre for Research on the Wider Benefits of Learning has found positive correlations between learning and health, including (Hammond, 2002):

- $\quad$ The adoption of positive health behaviors such as reduction in smoking and alcohol consumption, increase in exercise and adoption of better diet, all of which reduce national health-care costs.

- Increases in occupational self-direction, self-esteem, self-fulfillment and financial security - which are concomitants of occupational success.

- Development of autonomy, problem solving skills, social competence, and a sense of purpose and optimism for the future - which promote individual occupational fulfillment and good citizenship.

- $\quad$ Promotion of social responsibility, social values and social skills - which facilitate social cohesion and positive involvement by individuals in the local community.

\section{LIFELONG LEARNING - ADAPTED TO OLDER WORKERS' SPECIAL NEEDS}

Older people are not so much different from young people at work. They want to: a) start work on a sound footing, b) be developed and trained throughout their career, and c) have flexibility in the hours they work and the kind of work they do (Education and Culture DG, 2011). Currently, the traditional focus on formal training is making way for the concept of age-friendly work- places, which combine formal, non-formal and informal learning to encourage competence development in organizations that value and support learning for workers of all ages. However, training and learning approaches that work for younger generations are not necessarily effective for people in the last stage of their career (European Centre for the Development of Vocational Training, 2010).

Concerning older employees' learning, Naegele (2007) suggests some basic guidelines:

- $\quad$ No age limits in access to company-organized learning and training opportunities.

- $\quad$ Special motivation efforts, methodology and provision of support.

- $\quad$ Systematic evaluation.

- $\quad$ Analysis of the skills needs of the company and matching these with the available skills and individual educational status of older employees and utilizing them in the methodology and contents of training.

- Continuous observance of the individual educational status. 
- $\quad$ The conception of training opportunities as an integral part of career planning and not solely as jobspecific, correlating training schemes to the life-course.

- $\quad$ The learning and development conducive arrangement of work organization, e.g. within the framework of mixed-age teams and groups.

- $\quad$ Using older employees and their special qualifications both as facilitators of further education for older and younger employees, and as an organizational 'knowledge pool'.

Based on numerous research findings and on a wide range of good practice, some additional ideas are identified, which enable to organize learning that is "age-friendly":

- $\quad$ Older learners respond better to informal learning than formal (Berg, Chyung, 2008).

- $\quad$ Programs should be presented at a slower pace, allowing extended discussion and repetition, take existing skills into consideration (Foster, 2008).

- $\quad$ Mixing classes with their younger counterparts and incorporating both group and independent work are in keeping with older learner preferences (Pincas, 2007).

- $\quad$ Older learner confidence can be increased by incorporating their previous experiences into any training programs and taking into account their personal interests, whilst avoiding any potentially competitive situations within the learner group (Dworschak et al., 2006).

- $\quad$ Self-managed learning - based on intrinsic motivation and supported by: learning environment, didactic arrangement of the learning material that are in line with the needs and learning prerequisites of older employees - should be encouraged (Leibold, Voelpel, 2006).

- $\quad$ Formal assessments are also less desirable to older learners (Ferrier et al, 2008) and fear of assessments can be reduced through the use of self-assessment methods (Foster, 2008). As older learners sometimes find it easier to remember the overall message of a text, rather than detail, assessments for older learners should include (Foster, 2008): a) multiple choice questions, requiring recognition memory, b) essay questions, requiring the learner to discuss key points or the overall subject area more broadly, c) sufficient time, allowing older learners to recall the required information and detail, d) the provision of examples, adding meaning to subject areas, and e) large print reading materials.

However, stereotypes among employers are still prevalent. Popular stereotypes include the beliefs that older workers do not want to learn, they cannot learn, they have great difficulty learning new technology and an investment in their training provides a poor return (Gray, McGregor, 2003). Those negative stereotypes present the main challenges for older learners in the workplace and should be tackled, before implementing any other activity aiming to foster older workers' learning.

\section{CONCLUSION}

The growing proportion of older people in the workforce, and their increasing propensity to work beyond the official age of retirement, suggests that supporting the continuous education and skills development of older workers seems to be of crucial importance when enabling older employees to prolong their working lives while simultaneously holding long-term benefits for employers and society alike. Companies have experienced improved retention rates through tailoring training to older workers. This includes the promotion of further training and development in performance management, and the implementation of recognition and reward programs for skills development (Foster, 2008).

An important part of the necessary action towards increased senior employability takes place on a psychological level, and investing in lifelong learning programs becomes crucial, since it is not so much the age of senior workers themselves that determines employability, but the age of the knowledge they possess. Older employees can be just as productive and up-to-date as their younger counterparts, but their knowledge and skills need to be refreshed on a regular basis; therefore, life-long learning programs are an absolute necessity for keeping seniors in employment. The introduction of such programs is also a clear signal to older employees that they are not regarded as obsolete but are in fact still very much a valued resource to the company. 
Good practice in educating and training of older workers means ensuring that older workers are not neglected in training and career development, that opportunities for learning are offered throughout working life, that training methods are appropriate to older workers, and that positive action is taken where necessary to compensate for discrimination in the past. Education of older employees must address today's issues and challenges with appropriate new learning partnerships and learning tools that are flexible, adaptable, and easily updated and upgraded. Moreover, we should keep in mind, that differences in learning ability between individuals become greater with age (Maurer, 2007). Individual characteristics, which are important considerations for all learners, must therefore receive even greater consideration in the delivery of training programs for older learners.

Besides, there is a clear need for future research of this field aiming to develop detailed indicators on the motives, contextual conditions and decision-making processes of ageing people connected to participation in all types of lifelong learning. We should consider both major groups of factors that influence older employees' continuous education and learning processes: individual factors (ex. age perceptions, motivation and attitude towards learning, experience and having learning goals) and contextual factors (ex. workplace conditions, team climate, learning atmosphere) (Luger, Mulder, 2010).

Through scientific research, lifelong learning theories and concepts for all age groups should be developed and evaluated with the aim to support organizational and individual motivation intended to strengthen the links between learning and working processes, and to aid lifelong career planning.

The research should also focus on enterprises - developing and testing sustainable approaches to learning and competence development. Especially promising research opportunities exist in developing the framework for conceptual model of older workers' learning within the organization and at the same time in validating it in empirical studies.

\section{AUTHOR INFORMATION}

Jana Žnidaršič, Ph.D., is assistant professor the Department of Management and Organization at the Faculty of Economics, University of Ljubljana (http://www.ef.uni-lj.si/en/). Her research interests are in age management, business communication, economics of education, management process, organizational behavior, learning organization and new public management. She attended many international conferences, where she presented papers in her research areas and published several articles in Slovene, European, and US journals. More information at http://www.ef.uni-lj.si/pedagogi/pedagog.asp?id=356; or via e-mail: jana.znidarsic@ef.uni-lj.si.

\section{REFERENCES}

1. Bass, S. A. (1995). Older and active. In Bass S. A. (Ed.): Older and active: How Americans over 55 are contributing to society, (pgs. 1-9). New Haven: Yale University Press.

2. Berg, S. \& S. Chyung (2008). Factors that Influence Informal Learning in the Workplace. Journal of Workplace Learning 20(4), 229-244.

3. Bohlinger, S. \& van Loo, J. (2010). Lifelong learning for ageing workers to sustain employability and develop personality. In European Centre for the Development of Vocational Training: Working and ageing; Emerging theories and empirical perspectives, (pgs.: 28-57). Luxembourg: Publications Office of the European Union.

4. $\quad$ Carnevale, A. P. \& Stone, S. C. (1994). Developing the new competitive workforce. In Auerbach J. A., Welsh J. C. (Ed.): Aging and competition: Rebuilding the U.S. workforce, (pgs. 94-144). Washington D. C.: The National Council on the Aging \& the National Planning Association.

5. Charness, N., Kelley, C.L., Bosman, E.A., Mottram, M. (2001). Wordprocessing training and retraining: Effects of adult age, experience, and interface. Psychology and Aging 16(1), 110-127.

6. Craik, F.I.M., Salthouse, T.A. (2000). The handbook of aging and cognition, 2nd ed. Mahwah, NJ: Erlbaum. 
7. Delgoulet, C., Marquie, J.C. \& Escribe, C. (1997). Training older workers: Relationships between age, other trainee characteristics, and learning anxiety. In Kilbom Asa et al. (Ed.): Work after 45?, Proceedings and selected papers from the international scientific conference held in Stockholm, September 22-25 (pgs. 70-78). Solna: Arbetslivsinstitutet \& forfattarna, National Institute for Working Life.

8. Dunn, S. (2005). Effective Strategies for Training Older Workers. In Beatty P. T., Visser R. M. S. (ed.): Thriving on an Aging Workforce: Strategies for Organizational and Systemic Change, (pgs. 70-80). Malabar, Florida: Krieger Publishing Company.

9. Dworschak B., Buck, H. \& Schletz, A. (2006). Building Workplaces in Line With the Ageing Process. In T. Tikkanen \& B. Nyhan (Eds) Promoting Lifelong Learning For Older Workers: An International Overview. Luxembourg: Office for Official Publications of the European Communities/Cedefop.

10. Education and Culture DG (2011). "Work-force Transition to Support Active Ageing", International PAWT Conference, Ljubljana, 23. November. Policy Paper.

11. European Centre for the Development of Vocational Training (2010): Working and ageing; Emerging theories and empirical perspectives. Luxembourg: Publications Office of the European Union.

12. Ferrier, F., G. Burke \& C. Selby Smith (2008). Skills Development for a Diverse Older Workforce. Adelaide: NCVER.

13. Ford, G. (2005). Am I Still Needed? Guidance and Learning for Older Adults. Derby: Centre for Guidance Studies, University of Derby.

14. Foster, S. (2008). Mature Age Learners and Workers: A Review of the Literature. Melbourne: Work-Based Education Research Centre, Victoria University.

15. Gray, L. \& J. McGregor (2003). Human Resource Development and Older Workers: Stereotypes in New Zealand. Asia Pacific Journal of Human Resources 41(3), 338-353.

16. Griffiths, A. (1997). "Ageing, health and productivity: a challenge for the new millennium" Work and Stress, 11(3), 197-214.

17. Hammond, C. (2002). Learning to be Healthy. London: Centre for Research on the Wider Benefits of Learning, Birkbeck College. http://sl.kadis.si/sitedata/282/upload/File/POLICY_PAPER.pdf

18. Ilmarinen, J \& Tuomi, K. (2004). Past, Present and Future of Work Ability. In: Ilmarinen J \& Lehtinen S.: Past, Present and Future of Work Ability. People and Work - Research Reports 65, Finnish Institute of Occupational Health.

19. Ilmarinen, J. \& Rantanen, J. (1999). Promotion of work ability during ageing. American Journal of Industrial Medicine, 36(1), 21-23.

20. Ilmarinen, J. (1991). Ageing workers in the European Union - status and promotion of work ability, employability and employment. Helsinki: Finnish Institute of Occupational Health, Ministry of Social Affaire and Health, Ministry of Labour.

21. Ilmarinen, J. (2001). Aging workers. Occupational and Environmental Medicine, 58(8), 546-552.

22. Ilmarinen, J. (2004). Preface. In: Ilmarinen J \& Lehtinen S.: Past, Present and Future of Work Ability. People and Work - Research Reports 65, Finnish Institute of Occupational Health.

23. Ilmarinen, J. (2006). Towards a longer worklife! Ageing and the quality of worklife in the European Union. Finnish Institute of Occupational Health. Helsinki: Ministry of Social Affairs and Health.

24. Ilmarinen, J., Tuomi, K. \& Klockars, M. (1997). Changes in the work ability of active employees over an 11-year period. Scandinavian Journal of Work, Environment and Health, 23(1), 49-57.

25. Kaeter, M. (1995). Age-old myths. Training, 32(1), 61-64.

26. Kaufman, H.G. (1995). Salvaging displaced employees: job-obsolescence, retraining, and redeployment. In London, M. (ed.). Employees, careers, and job creation, (pgs. 105-120). San Francisco: Jossey-Bass.

27. Lazear, E. P. (1998). Personnel Economics for Managers. New York: John Wiley \& Sons.

28. Leibold, M. \& Voelpel, S. (2006). Managing the Aging Workforce; Challenges and Solutions. Publicis Corporate Publishing and Wiley.

29. Luger, B. \& Mulder, R. (2010). A literature review basis for considering a theoretical framework on older workers' learning. In European Centre for the Development of Vocational Training: Working and ageing; Emerging theories and empirical perspectives, (pgs.: 58-73). Luxembourg: Publications Office of the European Union.

30. Maurer, T. (2007). Employee Development and Training Issues Related to the Aging Workforce. In K. Shultz \& G. Adams (Eds) Aging and Work in the 21st Century. New Jersey: Lawrence Erlbaum Associates. 
31. McGregor, J. \& Gray, L. (2002, 1. junij). Stereotypes and Older Workers: The New Zealand Experience. Social Policy Journal of New Zealand, pp. 163-177.

32. Meadows, P. (2003). Retirement Ages in the UK: A Review of the Literature. Employment Relations Research Series No. 18. London: Employment Market Analysis and Research, The Department of Trade and Industry.

33. Meinz, E.J., Salthouse, T.A. (1998). The effects of age and experience on memory for visually presented music. Journal of Gerontology: Psychological Sciences, 53(1), P60-P69.

34. Mincer, J. (1974). Schooling, experience and earnings. New York: Columbia University Press.

35. Morrow, D., Leirer, V., Altieri, P., Fitzsimmons, C. (1994). When expertise reduces age differences in performance. Psychology and Aging 9(1), 134-148.

36. Naegele, G. (2007). Increasing Employment of Older Workers through Lifelong Learning. Peer Review, Iceland.

37. Newton, B. et al. (2005). Training a Mixed-Age Workforce: Practical Tips and Guidance. Brighton: Department for Work and Pensions, Institute for Employment Studies.

38. OECD (1996). Lifelong learning for all. Meeting of the Education Committee at Ministerial Level, 16-17 January, 1996. Paris: OECD.

39. Peterson, D. A. \& Wendt, P. F. (1995). Training and education of older Americans as workers and volunteers. In Bass S. A. (ed.): Older and active: How Americans over 55 are contributing to society (pgs. 217-236). New Haven: Yale University Press.

40. Pincas, A. (2007). How do Mature Learners Learn? Quality in Ageing and Older Adults 8(4), 28-32.

41. Rolland, L. (2004). The Age Chasm: Successfully Managing Age in Your Organisation. Drake Whitepaper Vol. 2, No. 5. Melbourne: Drake International.

42. Salthouse, T. A. \& Maurer, T. J. (1996). Aging, job performance, and career development. In Birren J. E. \& Schaie K. W. (ed.): Handbook of the Psychology of Aging (pgs. 353-364). London: Academic Press.

43. Salthouse, T.A. (2006). Mental exercise and mental aging: Evaluating the validity of the "use it or lose it" hypothesis. Perspectives on Psychological Science 1(1), 68-87.

44. Schaie, K. W. (1990). Intellectual development in adulthood. In Birren, J.E.; Shaie, K.W. (ed). Handbook of the psychology of aging, 3rd edition, (pgs. 183-200). San Diego, CA: Academic Press.

45. Silverstein, M. 2008. Meeting the Challenges of an Aging Workforce. American Journal of Industrial medicine, 51(4), 269-280.

46. Staudinger, U., Lindenberger, U. (2003). (ed). Understanding human development: lifespan psychology in exchange with other disciplines. Berlin: Kluwer Academic.

47. Sterns, H. L. \& Gray, J. H. (1999). Work, leisure, and retirement. In Cavanaugh J., Whitbourne S. K. (Ed): Gerontology: An interdisciplinary perspective (pgs. 355-389). New York: Oxford University Press.

48. Stoney, C. \& Roberts, M. (2003). The case for older workers at Tesco: An examination of attitudes, assumptions and attributes. Carleton: Carleton University, School of Public Policy and Administration.

49. Sullivan, S. E. \& Duplaga, E. A. (1997). Recruiting and retaining older workers in the new millennium. Business Horizons, 40(6), 65-69.

50. Thijssen, J.G.L. (1992). A model for adult training in flexible organisations. Journal of European Industrial Training, 16(9), 5-15.

51. Thijssen, J.G.L.; Van der Heijden, B.I.J.M. (2003). Evaporated talent? Problems with talent development during the career. International Journal of HRDM, 3(2), 154-170.

52. Thijssen, Y. \& Rocco, T. (2010). Development of older workers: revisiting policies. In European Centre for the Development of Vocational Training: Working and ageing; Emerging theories and empirical perspectives, (pgs.: 13-27). Luxembourg: Publications Office of the European Union.

53. Tuomi, K. et al. (2001). Promotion of work ability, the quality of work and retirement. Occupational Medicine, 51(5), 318-324.

54. Warr, P. (1998). Age, competence and learning at work. In Kilbom Asa (Ed.): Ageing of the Workforce, Key-note Presentations and Abstracts from a Workshop held in Brussels, March 23-24 (pgs. 23-62). Solna: Arbetslivsinstitutet, National Institute for Working Life. 